\title{
Correspondence
}

We welcome letters to the Editor concerning articles which have recently been published. Such letters will be subject to the usual stages of selection and editing; where appropriate the authors of the original article will be offered the opportunity to reply.

Letters should normally be under 300 words in length, double-spaced throughout, signed by all authors and fully referenced. The edited version will be returned for approval before publication.

\section{Reamed versus unreamed nails}

Sir,

We read with interest the article by Clatworthy et al $^{1}$ in the May 1998 issue entitled 'Reamed versus unreamed femoral nails: a randomised prospective trial'. The authors have carried out a randomised trial without any inclusion and exclusion criteria for either of the two groups under study. They performed reamed nailing in open fractures and reported breakage of the implant in cannulated nails of 10,11 and $12 \mathrm{~mm}$ diameter, but none using a solid nail of $9 \mathrm{~mm}$ diameter. They have cited reports of better results with AO unreamed femoral nails (UFN).

The unreamed nail is a specialised implant which is used for fractures of the femoral shaft with respiratory compromise because of pulmonary embolism and pre-existing lung disease or trauma, ${ }^{4,5}$, in open fractures of the femoral shaft in order to minimise the risk of infection ${ }^{6}$ and because of compromise of the periosteal blood supply, and in patients with multiple injuries to decrease the blood loss and duration of surgery.

In 17 patients who had unreamed femoral nailing for the above indications with a short follow-up we have not seen delayed union and breakage of the implant as reported by the authors. We have used only AO UFN of 9 and $10 \mathrm{~mm}$ diameter.

We feel that randomisation, irrespective of the type of fracture and general status of the patient, should not be used to select the implant, and is unethical. The quality of the implant used in the study should be re-assessed since nails of 10,11 and $12 \mathrm{~mm}$ diameter have broken and those of $9 \mathrm{~mm}$ diameter have not. The better results reported with the $\mathrm{AO}$ nail may be due to the fact that the UFN is a solid titanium nail and better designed.

In addition, the authors have neither mentioned nor compared the rate of infection in both groups.

J. L. BASSI

H. S. SELHI

Dayanand Medical College and Hospital

Ludhiana, India.

1. Clathworthy MG, Clark DI, Gray DH, Handy AE. Reamed versus unreamed femoral nails: a randomised, prospective trial. J Bone Joint Surg [Br] 1998;80-B:485-9.

(C1999 British Editorial Society of Bone and Joint Surgery 0301-620X/99/4102346 \$2.00

J Bone Joint Surg [Br] 1999;81-B:741-6.
2. Krettek C, Schulte-Eistrup S, Schandelmaier P, Rudolf J, Tscherne H. Osteosynthesis of femur shaft fractures with the AOfemur nail: surgical technique and initial clinical results with standard lock fixation. Unfallchirurg 1994;97:549-67.

3. Giannoudis PV, Furlong AJ, Macdonald DA, Smith RM. Reamed against unreamed nailing of the femoral diaphysis: a retrospective study of healing time. Injury 1997;28:15-8.

4. Pape HC, Regel G, Dwenger A, Sturm JA, Tscherne H. Influence of thoracic trauma and primary femoral intramedullary nailing on the incidence of ARDS in multiple trauma patients. Injury 1993;24: Suppl 3,82-103.

5. Pape HC, Regel G, Dwenger A, et al. Influence of different methods of intramedullary nailing on lung function in patients with multiple trauma. J Trauma 1993;35:709-16.

6. Singer RW, Kellam JF. Open tibial diaphyseal fractures: results of unreamed locked intramedullary nailing. Clin Orthop 1995;315: 114-8.

\section{Author's reply:}

Sir,

We thank Drs Bassi and Selhi for their interest. This study was designed in late 1994 when basic science and animal studies suggested that there would be a considerable benefit in treating all femoral fractures with an unreamed nail. ${ }^{1}$ Not only were patients with pulmonary trauma thought to benefit as a result of decreased fat embolism and hence decreased pulmonary morbidity, ${ }^{2-6}$ but it was predicted that the healing time would be reduced in all fractures with decreased cortical necrosis and less disruption of the blood supply by avoiding the reaming process. ${ }^{7-9}$ Further, the operating time and blood loss would be decreased. At the time there were no clinical papers comparing the unreamed nail with the reamed nail to support these theoretical premises.

We set up our trial to include all femoral fractures in skeletally mature patients and to exclude fractures within $6 \mathrm{~cm}$ of the knee or $4 \mathrm{~cm}$ of the lesser trochanter.

We strongly believe that the only way to determine if a new method is superior to an established technique is by a prospective, randomised trial. We find it disturbing that they state that randomisation of our patients was unnecessary and unethical. Rather, they quote their unpublished study of 17 patients with a short followup and a small non-randomised series by Pape et $\mathrm{al}^{5}$ to determine that the unreamed femoral nail is only indicated in patients with pulmonary compromise, open fractures and multiple injuries.

We agree that the unreamed nail is not indicated for isolated closed fractures. We can only state this after evaluation of our results and those of other large series from Giannoudis et al, ${ }_{13}^{10}$ Tornetta and Tiburzi, ${ }^{11}$ Anglen and Blue, ${ }^{12}$ Court-Brown et al ${ }^{13}$ and Hammacher, van Meeteren and van der Werken ${ }^{14}$ which confirm our findings. All of these papers were published well after our study had begun.

The role of reaming in patients with multiple injuries and pulmonary compromise is an area of considerable controversy. Pape et $\mathrm{al}^{6}$ in a small series showed a significant improvement in lung function with unreamed nails, but three large series ${ }^{15-17}$ have demonstrated no difference in pulmonary morbidity when reamed nailing is compared with other methods of fixation of a femoral fracture. A review of the most recent clinical and animal research on this subject was recently performed by Bone, Anders and Rohrbacher. ${ }^{18}$ They conclude that pulmonary failure seems to be secondary to pulmonary contusion, not to the method of fixation of the fracture. 
Certainly, the high rate of failure of the implant in our series is a concern and it is encouraging that the same problem has not occurred with the solid AO titanium nails. We did not mention rates of infection in our study since none occurred.

M. G. CLATWORTHY, FRACS

Toronto, Canada.

1. Pape HC, Weller S, Sturmer KM, et al. Pathophysiology of intramedullary nailing. Injury 1993;Suppl 3:1-103.

2. Tu YK, Lin CH, Su JI, Hsu DT, Chen RJ. Unreamed interlocking nail versus external fixator for open type III tibia fractures. J Trauma 1995;39:361-7.

3. Pell ACH, Christie J, Keating JF. The detection of fat embolism by transoesophageal echocardiography during reamed intramedullary nailing. J Bone Joint Surg [Br] 1993;75-B:921-5.

4. Strecker W, Gonschorek O, Fleischmann W, et al. Thromboxaneco-factor of pulmonary disturbances in intramedullary nailing. Injury 1993;24:Supp13:68-72.

5. Pape HC, Regel G, Dwenger A, Sturm JA, Tscherne H. Influence of thoracic trauma and primary femoral intramedullary nailing on the incidence of ARDS in multiple trauma patients. Injury 1993;24:Suppl 3:82-103.

6. Pape HC, Regel G, Dwenger A, et al. Influences of different methods of intramedullary femoral nailing on lung function in patients with multiple trauma. J Trauma 1993;35:709-16.

7. Danckwardt-Lilliestrom G, Lorenzi GL, Olerud S. Intramedullary nailing after reaming: an investigation on the healing process in osteotomised rabbit tibias. Acta Orthop Scand Suppl 1970;134:1-7.

8. Kessler SB, Hallfeldt KKJ, Perren SM, Schweiberer L. The effects of reaming and intramedullary nailing on fracture healing. Clin Orthop 1986;212:18-25.

9. Krettek C, Schulte Eistrup S, Schandelmaier P, Rudolf J, Tscherne H. Osteosynthesis of femur shaft fractures with the unreamed AOfemur nail: surgical technique and initial clinical results of standard lock fixation. Unfallchirurg 1994;97:549-67.

10. Giannoudis PV, Furlong AJ, Macdonald DA, Smith RM. Reamed against unreamed nailing of the femoral diaphysis: a retrospective study of healing time. Injury 1997;28:15-8.

11. Tornetta P, Tiburzi D. The treatment of femoral shaft fractures using intramedullary interlocked nails with and without intramedullary reaming: a preliminary report. J Orthop Trauma 1997;11:89-92.

12. Anglen JO, Blue JM. A comparison of reamed and unreamed nailing of the tibia. $J$ Trauma 1995;39:351-5.

13. Court-Brown CM, Will E, Christie J, McQueen MM. Reamed or unreamed nailing for closed tibial fractures: a prospective study in Tscherne C1 fractures. J Bone Joint Surg [Br] 1996;78-B:580-3.

14. Hammacher ER, van Meeteren MC, van der Werken C. Improved results in treatment of femoral shaft fractures with the unreamed femoral nail? A multicenter experience. J Trauma 1998;45:517-21.

15. Bone LB, Babikian G, Stegemann PM. Femoral canal reaming in the polytrauma patient with chest injury: a clinical perspective. Clin Orthop 1995:91-4

16. Carlson DW, Rodman GH, Kaehr D, Hage J, Misinski M. Femur fractures in chest-injured patients: is reaming contraindicated? $J$ Orthop Trauma 1998;12:164-8.

17. Bosse MJ, MacKenzie EJ, Riemer BL, et al. Adult respiratory distress syndrome, pneumonia and mortality following thoracic injury and a femoral fracture treated either with intramedullary nailing with reaming or with a plate: a comparative study. J Bone Joint Surg [Am] 1997;79-A:799-809.

18. Bone LB, Anders MJ, Rohrbacher BJ. Treatment of femoral fractures in the multiply injured patient with thoracic injury. Clin Orthop 1998;347:57-61.

\section{Pain in the assessment of total knee replacement}

Sir,

We read with interest the article by Murray and Frost ${ }^{1}$ in the May 1998 issue entitled 'Pain in the assessment of total knee replacement'. We wish to make several comments.
In none of our long-term studies ${ }^{2-5}$ have we found that knees tend to become more painful with time unless there is objective evidence of a cause such as loosening. The omission of the patellar component in most of the cases of Murray and Frost may be one cause of recurrent pain. We are aware that the need to resurface the patella has not been conclusively proved, but we believe that the available information is of too short-term a nature to show a difference. In our experience pain from a patella which has not been resurfaced occurs approximately five years after the arthroplasty - precisely the period observed by the authors. The design of the trochlear femoral component may also determine how well the native patella is accepted. For example, the IB prosthesis was designed to accommodate a dome-shaped patellar component.

It is difficult to identify co-morbidities, such as spinal stenosis or hip pathology which could produce pain in the area of the knee, in a questionnaire sent to elderly patients. There were many patients with rheumatoid arthritis in their series.

We agree with the authors that more sensitive tools are needed to assess the outcome of total knee replacement but question whether the use of recurrent pain is an appropriate endpoint.

We agree that incomplete follow-up matters very much when considering the reliability of survivorship analysis. A worst-case scenario in which patients lost to follow-up are considered failures is always necessary and we believe that survivorship analysis is meaningless without this information.

J. N. INSALL, MD

G. R. SCUDERI, MD

Insall Scott Kelly Institute for Orthopaedics and Sports Medicine New York, USA.

1. Murray DW, Frost SJD. Pain in the assessment of total knee replacement. J Bone Joint Surg [Br] 1998;80-B:426-31.

2. Colizza WA, Insall JN, Scuderi GR. The posterior stabilized total knee prosthesis: assessment of polyethylene damage and osteolysis after a ten-year-minimum follow-up. J Bone Joint Surg [Am] 1995; 77-A:1713-20.

3. Diduch DR, Insall JN, Scott WN, Scuderi GR, Font-Rodriguez D. Total knee replacement in young, active patients: long-term follow-up and functional outcome. J Bone Joint Surg [Am] 1997;79-A:575-82.

4. Stern SH, Insall JN. Posterior stabilized prosthesis: results after follow-up of nine to twelve years. J Bone Joint Surg [Am] 1992; 74-A:980-6.

5. Vince KG, Insall JN, Kelly MA. The total condylar prosthesis: 10- to 12-year results of a cemented knee replacement. J Bone Joint Surg [Br] 1989;71-B:793-7.

\section{Author's reply:}

Sir,

We are pleased that Drs Insall and Scuderi agree that patellar resurfacing has not been shown to reduce pain.

Traditional methods of assessment, such as survival analysis with revision as the endpoint, suggest that virtually all total knee replacements are successful at ten years. If this was true then no further effort would need to be directed towards improving total knee replacement. We have shown, however, that this is not the case since a substantial proportion of patients had pain at some stage. We did not determine why they had pain, and, as Drs Insall and Scuderi suggest, there are many possible reasons. We agree that further work is needed using other methods of assessment to determine the various causes of pain and then to develop techniques to prevent it. Having done this, the way to determine whether these techniques have been successful is to use a method of assessment similar to that in our study.

D. W. MURRAY, MD, FRCS Orth

Nuffield Orthopaedic Centre

Oxford, UK 


\section{Open acromioplasty does not prevent the progression of an impingement syndrome to a tear}

Sir,

I read with interest the article by Hyvönen et al $^{1}$ in the September 1998 issue entitled 'Open acromioplasty does not prevent the progression of an impingement syndrome to a tear'. Their conclusion is given in the title. I believe that, given their data, it is reasonable to decide exactly the opposite, namely, that acromioplasty does prevent tears.

Their study showed that about $20 \%$ of cases of impingement without associated tears of the cuff went on to sustain a tear. In the absence of a control group for comparison, meaningful inferences cannot be made. If the baseline rate of progression was $100 \%$, then acromioplasty gives a reduction of $80 \%$ in the risk, and can reasonably be described as 'preventing' tears. If, on the other hand, the baseline risk was closer to the rate of $20 \%$ observed after surgery, then the authors' conclusions are justified. As described, we simply do not know.

The theories regarding the pathogenesis of tears of the rotator cuff are vigorously contested. Researchers ask whether the acromion causes or abets the process. A study which shows that acromioplasty does not prevent tears sheds light on that debate. Unfortunately, this article does not.

J. BERNSTEIN, MD

University of Pennsylvania

Philadelphia, USA.

1. Hyvönen $\mathbf{P}$, Lohi $\mathbf{S}$, Jalovaara $\mathbf{P}$. Open acromioplasty does not prevent the progression of an impingement syndrome to a tear. $J$ Bone Joint Surg [Br] 1998;80-B:813-6.

\section{Author's reply:}

Sir,

We thank Dr Bernstein for his comments regarding our interpretation of our data. On the basis of clinical experience we know that the baseline of the progression of the impingement syndrome from tendinitis to tear is not $100 \%$, since conservative treatment is successful in many cases in the initial phase and there is no evidence to suggest that all of these would later develop into a tear. The assumption that an impingement syndrome would only follow mechanical compression exerted by the acromion on the cuff would mean that relief of compression would interrupt the inflammatory process in the cuff and no tears would appear after acromioplasty. If we had not found any tears in our long-term follow-up study it might have been concluded that the mechanical theory of the pathogenesis of the impingement syndrome is true. We observed a tear of the cuff in $20 \%$ of our cases which suggests that primary degeneration of the cuff is in some way involved in the pathogenesis of the impingement syndrome. In this sense, we consider our title to be justified. We assume that many questions remain open: What is the role of age-related degeneration in the impingement syndrome? Is this deterioration primary or is it caused by the acromion? etc. Before our study there was no information available on the long-term condition of the cuff after acromioplasty.

P. JALOVAARA, MD, PhD

University of Oulu

Oulu, Finland.

\section{Retroversion of the acetabulum}

Sir,

I read with interest the article by Reynolds et $\mathrm{al}^{1}$ in the March 1999 issue entitled 'Retroversion of the acetabulum'.
The aetiology of unilateral osteoarthritis in the middle-aged adult has been always difficult to determine. Subtle changes in the morphology of both sides of the hip must predispose areas of the joint to increased wear. The authors go some way to explaining some of these changes and this is supported by clinical practice. Whether or not a major periacetabular osteotomy is indicated is questionable especially when there are no hard data on the natural history.

I must question, however, Figures 5 and 6 . The described 'cross-over sign' must be of doubtful significance. Figure 5 illustrates a normal acetabulum. The rotation of the hemipelvis suggests that this is more of an obturator view. This view, as described by Letournel and Judet, ${ }^{2}$ moves the anterior wall well inside the posterior wall. Figure 6 illustrates the 'cross-over sign', but this radiograph is much more of an iliac oblique view. Unlike in Figure 5 the ischial spine is clearly visible which indicates a considerable amount of rotation. In an iliac oblique view the anterior wall is moved more laterally. This is a commonly recognised phenomenon in the interpretation of acetabular fractures. The phenomenon described by Reynolds et al is further exaggerated by the fact that Figure 5 is much more of a standard AP view whereas Figure 6 approaches a true classical inlet view. In the latter the anterior wall is again brought above and lateral to the posterior wall. Both illustrations also show a different degree of rotation of the femoral shaft.

These changes in rotation will explain the described radiological findings and therefore I believe that the radiological 'cross-over sign' is unreliable. CT is a more acceptable way of assessing the orientation of the cup. I am intrigued by Figures 8, 9 and 10. If one is to assume that this condition represents malalignment of the acetabulum I would have expected such changes to occur on the posterior rather than on the anterior aspect of the acetabulum.

M. D. BIRCHER, FRCS

St George's Hospital

London, UK.

1. Reynolds D, Lucas J, Klause K. Retroversion of the acetabulum: a cause of hip pain. J Bone Joint Surg [Br] 1999;81-B:281-8.

2. Letournel E, Judet R. Fractures of the acetabulum. 2nd edition. Berlin, etc: Springer-Verlag, 1993.

\section{Author's reply:}

Sir,

The purpose of our article was to draw attention to this significant anomaly since it usually goes unrecognised in the routine reporting of standard radiographs. We agree with $\mathrm{Mr}$ Bircher that acetabular retroversion is best assessed by CT. For reasons of exposure and cost alone, this is not an examination which should be part of the first assessment. We argue that in practice an informed examination of plain anteroposterior (AP) radiographs can indicate where this more extensive procedure is justified.

Figures 5 and 6 are two of the 310 routine AP radiographs from patients in our study. We selected them as examples to illustrate the point. For such routine exposures a radiographer is able to standardise pelvic alignment in the coronal and axial planes, and can ensure that the x-ray beam is vertical. It is less easy similarly to control the sagittal plane. This is dependent on the degree of flexion or extension at the lumbosacral junction and even more on the size and shape of the patient. Variations are common, can be marked, and certainly do influence appearances in the images. We emphasise this in the caption to Figure 5. The question of differences in rotation of the femoral shaft seems less relevant.

Our point is that the appearance of a 'cross-over sign' in a plain film should heighten awareness of the advisability of proceeding 
to full CT assessment. We agree that the cross-over sign is not an invariable accompaniment of every instance of retroversion, particularly of those of a less degree. The sign was present in all of our patients who had persistent symptoms and in whom the retroversion had reached the $15^{\circ}$ or more which we describe as significant.

In considering Figures 8, 9 and $10 \mathrm{Mr}$ Bircher has assumed that in retroversion deficiency of the posterior cover is the damaging element. In the text the point is made that, on the contrary, it is impingement at the anterosuperior acetabular edge which seems to cause the problem. We remark specifically that we were unable to show reduction of the area of the posterior articular surface.

D. REYNOLDS, FRCS

St Thomas' Hospital

London, UK

\section{Neonatal detection of developmental dysplasia of the hip (DDH)}

Sir,

With reference to the editorial in the November 1998 issue by Jones ${ }^{1}$ entitled 'Neonatal detection of developmental dysplasia of the hip (DDH)' it was with some sadness that I read this excellent review of the current situation on neonatal screening, particularly the view that clinical screening was not only ineffective but not justified. This is just the material that managers need in order to withdraw funding for effective screening programmes.

I am in total agreement with Mr Jones that the examiners are inexperienced and poorly taught and that there is a need for orthopaedic surgeons to be active in screening, but this is the nub of the problem, not criticism of the technique of manual detection of hip instability in the newborn. The success rate of $90 \%$ achieved in our group in the prevention of establishing 'walking' $\mathrm{CDH}$ was published as a 20 -year review ${ }^{2}$ in the Journal but was not quoted by Mr Jones.

Subsequently, I presented to the New Zealand Orthopaedic Association, the follow-up at 30 years, which remain consistent. The results of the 40-year study will be given in due course.

I may have been remiss in not submitting my more recent paper for publication but find the criteria for this rather daunting.

I would agree with Mr Jones that all methods of surveillance are fallible but, in this country of the no-fault principle, we have been lucky in not having the deterrent of medicolegal fears. The rate of failure of this difficult examination lies with the examiners, who should always be qualified orthopaedic surgeons, examining a minimum of 500 cases per year in order to maintain expertise. It is not an examination for the inexperienced or those not familiar with the biomechanics of the hip.

V. HADLOW, FRCS, FRACS

Fulford Orthopaedic Clinic

New Plymouth, New Zealand.

1. Jones D. Neonatal detection of developmental dysplasia of the hip (DDH). J Bone Joint Surg [Br] 1998;80-B:943-5.

2. Hadlow V. Neonatal screening for congenital dislocation of the hip. $J$ Bone Joint Surg [Br] 1988;70-B:740-3.

\section{Author's reply:}

Sir,

I thank Mr Hadlow for his letter and apologise for not referring to his valuable paper.

His message is important. We should not be deflected from urging a strong clinical screening programme just because the present one is failing us through lack of expertise of the examiners and too few experienced orthopaedic surgeons. How these deficiencies are to be addressed is part of any continuing debate.

D. JONES, FRCS, FRCS Ed(Orth)

Hospital for Sick Children

London, UK.

\section{Patterns of weight distribution under the metatarsal heads}

Sir,

We read with interest the paper in the March 1999 issue by Luger et $\mathrm{al}^{1}$ entitled 'Patterns of weight distribution under the metatarsal heads'. This shows that in most healthy subjects the pressures recorded under the second to fourth metatarsal heads are higher than those under the first and fifth heads using the authors' system. They infer from this that there is no distal metatarsal arch during the stance phase of walking and that they were the first to quantify this.

Pressure under the metatarsal head does not necessarily reflect position. The pressure is a reflection of load, surface area and soft tissue between the metatarsal head and platform. Betts et $\mathrm{al}^{2}$ using an optical pedobarograph in 50 feet have shown quantitatively that the pressures under the second to the fourth metatarsals are higher than those under the first and fifth during walking.

N. J. HARRIS

J. CHELL

T. W. D. SMITH

Sheffield Children's Hospital

Sheffield, UK.

1. Luger EJ, Nissan M, Karpf A, Steinberg EL, Dekel S. Patterns of weight distribution under the metatarsal heads. J Bone Joint Surg [Br] 1999;81-B:199-202.

2. Betts RP, Franks CI, Duckworth T. Foot pressure studies: normal and pathological gait analysis. In: Jahss MH, ed. Disorders of the foot and ankle - medical and surgical management. 2nd ed. Philadelphia: W. B. Saunders, 1991:484-519.

\section{Author's reply:}

Sir,

We agree with the statement that pressure reflects load, surface area and soft tissue, but we believe that the most important factor reflected by the load is the underlying bony structure.

We did not find the paper by Betts et $\mathrm{al}^{1}$ in our literature search. They showed the pressure under the second to the fourth metatarsal heads to be higher than under the first and fifth heads in 50 healthy subjects, as observed by us, and were the first to publish this observation. We apologise for our unsubstantiated claim. The existence of a forefoot transverse arch is still considered a fact by many physicians and scientists. We hope that our work carried out on a much larger sample will lead to the recognition of the true functional anatomy of the foot.

The lack of a transverse arch in pathological feet has not been reported. The combination of a large number of feet, both normal and pathological, and the use of a highly accurate system of measurement have led us to conclude that the existence of a transverse arch is abnormal.

M. NISSAN, PhD

Tel-Aviv Sourasky Medical Centre

Tel-Aviv, Israel.

1. Betts RP, Franks CI, Duckworth T. Foot pressure studies: normal and pathological gait analysis. In: Jahss MH, ed. Disorders of the foot and ankle-medical and surgical management. 2nd ed. Philadelphia: W. B. Saunders, 1991:484-519. 


\section{Infections associated with dental procedures in total hip arthroplasty}

Sir

I write concerning the paper by LaPorte et $\mathrm{al}^{1}$ published in the January 1999 issue entitled 'Infections associated with dental procedures in total hip arthroplasty'.

The authors assume that $6 \%$ of their late infections in total hip arthroplasty are associated with a dental procedure, and that prophylactic antibiotic treatment should be considered by patients with systemic disease or who are undergoing extensive procedures.

They comment on the very different rates of infection associated with dental procedures among all infected total hip arthroplasties reported in the literature, from $0.04 \%$ to $6 \%$; this indicates the prevalence of this type of contamination. There is no definite answer which will account for these differences, but one reason may be differences in the dental status of the patients in these studies. It is questionable whether prophylactic antibiotic treatment can be advocated based only on a high rate of prevalence.

The fundamental question is: What is the incidence of infection after dental procedures on patients with total hip arthroplasty? As far as I know, there is no answer at present, since it would be very difficult to organise such a study. This, however, is the only way to compare the cost-benefit ratio as to whether or not to give prophylactic antibiotic treatment to patients with a total hip arthroplasty when having dental procedures. There is also the risk of antibiotic-related complications. Conclusions drawn only on prevalence rates are a matter of opinion.

J.-Y. JENNY, MD

Centre de Traumatologie et d'Orthopédie

Illkirch Graffenstaden, France.

1. LaPorte DM, Waldman BJ, Mont MA, Hungerford DS. Infections associated with dental procedures in total hip arthroplasty. J Bone Joint Surg [Br] 1999;81-B:56-9.

\section{Authors' reply:}

Sir,

We agree with Dr Jenny that the definitive study is probably not feasible because of the large number of patients required. The American Dental Association and the American Academy of Orthopaedic Surgeons have now recommended that antibiotic prophylaxis for routine dental procedures is no longer indicated. We believe that our paper supports the likelihood that immunocompromised patients, as well as those undergoing extensive procedures, do not fall into the 'common' category. Because of the disastrous nature of an infected total hip replacement, we believe that these subsets of patients still warrant prophylactic antibiotic cover.

M. A. MONT, MD

D. S. HUNGERFORD, MD

D. M. LAPORTE, MD

B. J. WALDMAN, MD

Good Samaritan Hospital

Baltimore, USA.

\section{Salvage of the head of the radius after fracture-dislocation of the elbow}

Sir,

We read with interest the article by Patel and Elliott in the March 1999 issue entitled 'Salvage of the head of the radius after fracture-dislocation of the elbow'.
We wish to congratulate them on their successful treatment of a challenging fracture, but we query their inclusion of this fracture within the Mason classification. ${ }^{2}$ The original classification referred to fractures of the radial head only and was modified by Johnston $^{3}$ to include dislocation of the elbow. Further modifications such as those of Morrey ${ }^{4}$ have assessed the effect of associated fractures and dislocations on injuries to the radial head with recommendations for treatment of the fracture on its own merits by excision and/or replacement when there is associated instability. Hotchkiss ${ }^{5}$ also added completely displaced fractures of the radial neck to the Mason-III category and recommended salvage when the head was intact. While this fracture has benefited from the application of these principles, the associated comminution of the proximal radial neck and shaft extends beyond their scope and we would question placing the fracture within this classification because of the principles of treatment.

We were only able to find one classification into which it could be placed, ${ }^{6}$ in which it would be AO 21.B3.1(2), i.e., a fracture of the proximal radius and ulna which combines a simple articular fracture of the ulna (the coronoid) and an extra-articular multifragmentary fracture of the radius.

\section{J. CHELL, FRCS Orth}

N. HARRIS, FRCS

Sheffield Children's Hospital

Sheffield, UK.

1. Patel VR, Elliott DS. Salvage of the head of the radius after fracturedislocation of the elbow: a case report. J Bone Joint Surg [Br] 1999; 81-B:306-8.

2. Mason ML. Some observations on fractures of the head of the radius with a review of one hundred cases. Br J Surg 1954;42:123-32.

3. Johnston GW. A follow-up of one hundred cases of fracture of the head of the radius with a review of the literature. Ulster Med J 1962; 31:51-6.

4. Morrey BF. Current concepts in the treatment of fractures of the radial head, the olecranon, and the coronoid. J Bone Joint Surg [Am] 1995; 77-A:316-27.

5. Hotchkiss RN. Displaced fractures of the radial head: internal fixation or excision? J Am Acad Orthop Surg 1997;5:1-10.

6. Müller ME, Nazarian S, Koch $\mathbf{P}$, Schatzcher J. The comprehensive classification of fractures of long bones. Berlin, etc: Springer Verlag, 1990.

\section{Authors' reply:}

\section{Sir,}

Messrs Chell and Harris have expressed concern about the inclusion of the injury which we described in the Mason classification ${ }^{1}$ or its modifications. The most widely quoted classification of fractures of the radial head is that of Mason. For reasons not entirely clear in his original paper, Mason excluded fractures of the radial head associated with dislocation of the elbow, despite his recognition that the two injuries should be considered part of the same traumatic process. He also excluded fractures of the radial neck. We accept that if we adhere strictly to Mason's criteria, the injury which we described does not fit the original Mason classification.

Most recent references logically include fractures of the radial neck in Mason's classification. ${ }^{2-4}$ The importance of recognising associated injuries, such as dislocation of the elbow, when dealing with fractures of the radial head has also been emphasised. Hotchkiss has modified the Mason classification based on clinical signs, radiological appearance and associated injuries ${ }^{3-4}$ and has outlined principles of treatment based on this. The injury which we described clearly satisfies the criteria for a type-III fracture with an associated injury in Hotchkiss's modification of the Mason classification ${ }^{4}$ and we have treated it based on the principles outlined by Hotchkiss. 
While we are aware that the bony injuries in our patient may fit into the AO 21.B3.1(2) category of the comprehensive classification of fractures, the latter has a number of limitations. It is recognised that, in practice, it is not very helpful in distinguishing the different patterns of fracture of the radial head ${ }^{7}$ and it does not take account of associated injuries such as dislocation of the elbow. We are not aware of any publications on fractures of the radial head which recommend treatment based on the comprehensive classification of fractures. We chose therefore not to use this classification in our description of the injury.

\section{R. PATEL, FRCS Orth \\ D. S. ELLIOTT, FRCS Orth \\ St Peter's Hospital \\ Chertsey, UK.}

1. Mason ML. Some observations on fractures of the head of the radius with a review of one hundred cases. Br J Surg 1954;42:123-32.
2. Jupiter JB, Mehne DK. Trauma to the adult elbow and fractures of the distal humerus. In: Browner BD, Jupiter JB, Levine AM, et al, eds. Skeletal trauma: fractures, dislocations, ligamentous injuries. Vol 2. Philadelphia: W. B. Saunders, 1992:1125-75.

3. Hotchkiss RN. Fractures and dislocations of the elbow. In: Rockwood CA, Bucholz RW, Green DP, Heckman JD, eds. Rockwood and Green's - fractures in adults. 4th ed. Philadelphia: Lippincott-Raven, 1996;1:929-1024.

4. Hotchkiss RN. Displaced fractures of the radial head: internal fixation or excision? J Am Acad Orthop Surg 1997;5:1-10.

5. Morrey BF. Current concepts in the treatment of fractures of the radial head, the olecranon and the coronoid. J Bone Joint Surg [Am] 1995; 77-A:316-27.

6. Müller ME, Nazarian S, Koch P, Schatzker J. The comprehensive classification of fractures of long bones. Berlin, etc: Springer-Verlag, 1990.

7. Schatzker J. Fractures of the radial head. In: Schatzker J, Tile M, eds. The rationale of operative fracture care. $2 \mathrm{nd}$ ed. Berlin, etc: SpringerVerlag, 1996:121-5. 